\title{
ESPETACULARIZAÇÃO E MORTE NAS REDES SOCIAIS
}

\author{
Edla Maria Silveira Luz ${ }^{1}$ \\ Heloísa Juncklaus Preis Moraes²
}

\section{INTRODUÇÃO}

Iniciamos o debate com a visão ampla que Guy Debord destacou em seu livro mais conhecido como "A sociedade do espetáculo" (1967), onde condenou ideias sobre a crítica do espetáculo e a reconstrução da própria existência humana.

Em sua afirmação de que o espetáculo não é um conjunto de imagens, mas uma relação social entre pessoas, mediada por imagens, Guy Debord faz uma leitura que nos remete ao espetáculo social que culturalmente vivemos através de imagens e como nos posicionamos através delas.

Dentro das afirmações de Debord a proposta ultrapassa a vida e se inclina na morte "exibida" e compartilhada através das redes sociais como uma forma de visibilidade e espetacularização.

\section{METODOLOGIA}

A metodologia segue a ordem da sociologia compreensiva que preocupa-se com o que é e não com o que deve-ser, na dinâmica existente nas relações sociais depositárias de crenças, valores, atitudes e hábitos adquiridos nas vivências e nas experiências cotidianas resultantes da ação humana (MORAES, 2012). Conforme Nóbrega (2012), tudo o que diz respeito à vida quotidiana experiências vividas, crenças e interações com as pessoas e com o ambiente - deve ser levado em conta, tanto do ponto de vista sociológico como em outras áreas do conhecimento. Nóbrega (2012, p. 375), comentando a obra de Maffesoli, aponta que aquele autor advoga que o racionalismo estático, símbolo do pensamento moderno,

\footnotetext{
${ }^{1}$ PPGCL-Unisul. edla.luz@unisul

2 PPGCL-Unisul. heloisapreis@hotmail.com
} 
deve dar lugar à racionalidade aberta da pós-modernidade, que apela para o entusiasmo e para o instinto. É o que chama de "razão sensível".

\section{RESULTADOS E DISCUSSÃO}

Estão alinhados nas ideias compartilhadas nas redes sociais e que acabam influenciando o pensamento e reflexões das pessoas quanto suas atuações. Ver na contemporaneidade é tudo, não importa, precisamos do visível, só existe o que é publicado e exposto, o que está ali em nossa tela, aos nossos olhos, o show da vida em questão, da vida dos outros. Nesse sentido, o espaço democrático da internet reconfigura o modo de pensar comunicação. Isso porque esses novos meios de expressão aumentaram a quantidade de produtores de mensagens independentes. Por vezes, eles se escondem atrás do suposto anonimato ou de perfis falsos, máscaras para a preservação da identidade. Na contramão desse processo, outros usuários buscam visibilidade e promoção da autoimagem no ciberespaço, através da disseminação massiva dos selfies e outros conteúdos autobiográficos por vezes forjados, que muitas vezes também funcionam como máscaras (HOFFMAN, 2015).

Para compreendermos melhor a repercussão da imagem nas redes sociais e

da espetacularização da morte, nos debruçamos sobre a imagem da pessoa "morta" nas redes sociais em perfil de de faceboock, instagram ou qualquer mídia interativa. A imagem nas redes sociais, da pessoa que já, fisicamente não está viva, pertence agora aos inúmeros comentários de colegas, parentes, amigos e curiosos que deixam recados e curtem as fotos da pessoa como se estivessem realmente falando com a imagem, "com a pessoa". A situação enunciada é repetida inúmeras vezes nos perfis de redes sociais de pessoas mortas e pode até ser considerada tão absurda que se questiona a necessidade de registrar comentários para a foto da pessoa e compartilhar comentários como se estivesse "dando" um recado para a foto da pessoa que já é considerada sem vida, morta. Diante do espetáculo, e que tal representação sobre o olhar do outro e sobre a imagem da pessoa já morta, nos provoca a reflexão de imaginar que tal experiência possa transferir uma mera ilusão de morte, ou até mesmo uma autoafirmação de não aceitação dela, da morte? O que antes era vivenciado diretamente, tornou-se 
representação (DEBORD, 1997), e o indivíduo acredita existir somente a partir da aceitação dos membros da rede. As pessoas preferem a imagem e a representação à realidade, passando a viver em uma ilusão. No duplo das trocas simbólicas que ocorrem nas redes sociais, a fotografia confere status, vira objeto de ostentação, sempre com foco no outro, em impressioná-lo.

Debord (1997) explica que o homem anula seus desejos e percepções em busca de verdades construídas, alienando-se. O selfie representa a busca pela aceitação e o ápice da autoidolatria, da devoção à autoimagem. Se para existir é preciso ser reconhecido pelo outro, principalmente quando ele atribui à imagem um "curtir", o selfie deve ser atraente e bem elaborado. A morte entra em cena nessa espetacularização e enquanto na "vida real" a única coisa a fazer é dar pêsames, o mundo virtual permite fazer da tragédia uma piada. Assim como acontece o movimento contrário, quando indivíduos se apropriam das imagens dos veículos de comunicação e as divulgam em seus perfis. E quem "curte", compartilha, e atesta o sucesso da postagem do usuário (HOFFMAN, 2015).

É na afirmação de que existe um confronto entre a percepção corporal da finitude e do tempo, que Ferreira-Santos e Almeida (2012) sugerem que esses confrontos acabam por escorrer de forma incontrolável na produção de imagens e símbolos, na articulação de narrativas míticas que irão produzir novos sentidos ao acontecimento mortífero.

Nesse campo de representação do imaginário, o pensamento manifesta as imagens através das conexões que dão uma ideia do que é pensado, sonhado e não vivenciado e por isso pode-se afirmar que essas conexões do real e do pensado provocam manifestações que são vistas como parte da realidade, apresentam sentido e automaticamente colocam o indivíduo em relação com o mundo e tudo o que o cerca (LUZ,2015).

Assim, o imaginário ganha força quando se demonstra que ele não se distancia do real, mas que considera elementos que dão ao real mais complexidade. Sob esse ponto de vista, a imaginação ganha um lugar de destaque, porque passa a ser necessária à vida humana, não por falar das coisas que não existem, mas porque essas coisas criam sentidos para a existência humana e participam da realidade (PERES, 2009).

As análises do que é explorado através do facebook demonstram que as pessoas costumam fazer referências à pessoa que já morreu como se esta 
estivesse viva. Se utiliza a página (perfil) da pessoa para que se elogie a mesma, falando de fatos ocorridos e até mesmo de fatos que não chegaram a ocorrer, como uma forma de "conversa" com quem já não está mais vivo e impossibilitado de realizar as leituras ali exploradas.

Essa situação acaba por representar a estimulação da vida privada, dentro da cultura "do querer ser visto", independentemente de que forma, considerando até a imaginação de poder "falar" com a pessoa morta através das redes sociais, aqui especificamente através do perfil no facebook.

Através destes relatos e mensagens àquela pessoa que já morreu, se evidenciam novos comentários e postagens, "curtidas" e compartilhamentos diversos, explorando a mensagem em uma reflexão do imaginário colocado como visibilidade e necessidade de afirmação potencializada através da imagem envolvendo neste caso a imagem e o perfil da pessoa que já morreu.

\section{CONCLUSÃO}

O termo imaginário é cada vez mais utilizado na sociedade com a ideia de depósito de imagens, sentimentos, lembranças e experiências, com a propriedade de impulsionar a pessoa a uma realização e afirmação da realidade e de tudo o que se constrói. Para alguns pensadores, como Nietzsche, essa realidade também se constitui em uma vontade de potência mediante os significados colocados em nossas representações e manifestações criadas nas possibilidades do "vir a ser" e constituídas pelo ser, pela matéria, pelo corpo e em seus desenvolvimentos e ideias na ação do cosmos. Inicia-se a reflexão acerca da ética da estética propondo-se ao pensamento a ideia de que "o imaginário sempre comunicou o estético na exploração das imagens dos sonhos, dos mitos, pelos processos criativos, e possibilitou o encontro de caminhos para a fantasia ou 0 fantástico" (RAHDE, 2007, p. 2).

A análise nos mostrou que a relação virtual coloca-se como latente, disponível, online, mesmo quando se trata de morte. O perfil da pessoa já falecida funciona como canal e possibilita um contato, tal como todos os outros realizados em rede social: desabafo, despedida, mensagem, comentário, curtidas. Debord (1997) já antevia e, como conceito, dizia que a sociedade do espetáculo não se limitava a um conjunto de imagens, mas a mediação da vida social por imagens. E é 
isto que vemos. Os depoimentos dão conta de um diálogo com um ser que está ali porque sua imagem está. E, mais do que isso, é uma imagem mundo de que pela tecnologia, pelo ambiente virtual, temos um canal de comunicação irrestrito, que nem a morte desfaz. A função do imaginário é criar atitudes imaginativas para dar conta da consciência da finitude. Conversar com quem já morreu pelo seu perfil em rede social é uma possibilidade de potência desta tecnologia do imaginário (SILVA, 2003).

\section{REFERÊNCIAS}

DEBORD, G. A sociedade do espetáculo. Rio de Janeiro: Contraponto, 1997.

HOFFMANN, Maria Luisa. OLIVEIRA, Michel de. A espetacularização da morte: um estudo de caso do selfie no velório de Eduardo Campos. INTERCON- Rio de Janeiro, 2015.

LUZ, Edla Maria Silveira.O lugar místico da intimidade no imaginário contemporâneo: o parto filmado como espetáculo.Tese de Doutorado.UNISUL, 2015.

MORAES, Heloisa Juncklaus Preis. A descoberta e a vivência do virtual: experiências infantis. Florianópolis: DIOESC, 2012.

NÓBREGA, Juliana Fernandes da. A sociologia compreensiva de michel maffesoli: implicações para a pesquisa em enfermagem. Trabalho apresentado à disciplina de mestrado "Concepções teórico-filosóficas no processo de cuidar em enfermagem e saúde" do Programa de Pós-Graduação em Enfermagem da Universidade Federal de Santa Catarina - Pen UFSC, 2012.

PERES, Lúcia Maria Vaz; EGGERT, Edla; KUREK, Deonir Luís. Essas coisas do imaginário... Diferentes abordagens sobre narrativas (auto) formadoras. São Leopoldo: Oikos; Brasília: Liber Livro, 2009.

RAHDE, Maria Beatriz Furtado; DALPIZZOLO, Jaqueline. Considerações sobre uma estética contemporânea. Revista da Associação Nacional dos Programas de Pós-Graduação em Comunicação, 2007.

SANTOS-FERREIRA, Marcos; ALMEIDA, Rogério. Aproximações ao Imaginário: bússola de investigação poética. São Paulo: Képos, 2012.

SILVA, Juremir Machado da. As tecnologias do Imaginário. Porto Alegre: Sulina, 2003. 